\title{
Implementation of sun-protection devices in industrial buildings with roof system of natural illumination in regions with hot and sunny climatic conditions
}

\author{
Sergey Stetsky ${ }^{1}$ and Tatiana Shchelokova ${ }^{1, *}$ \\ ${ }^{1}$ Moscow State University of Civil Engineering, Yaroslavskoye shosse, 129337, 26, Moscow, Russia
}

\begin{abstract}
The article describes main objects of sun-protection devices implementation in premises of industrial buildings. The study deals with the above mentioned elements, used for buildings with roof system of natural lighting, located in regions with hot and sunny climate. The use of sunprotection in such an outdoor conditions is widely known, but in most cases their implementation is connected with civil buildings. Different structures of roof lighting system are being considered in the article under two main criteria: a sun-protection quality and quantity of natural light, penetrated into the interiors. The conclusion was maid, that the best type of natural lights structures are monitors, equipped with canopies. These are the best in general, with respect not only to insolation limitation and natural
\end{abstract}

\section{Introduction}

Its well known, that the roof lighting system, which provides natural illumination of interiors through skylights, sheds or monitors is much more efficient than ordinary sidelighting system. $[1-8,12]$

The former system is widely employed in industrial or public buildings, while the latter one is traditionally used in every functional type of buildings, especially in civil construction. In majority of industrial buildings, which are being discussed within our study, both lighting systems are being used together, in order to increase the levels of natural lighting of interiors to a maximum possible degree and hence, to increase a labour productivity. [8-11].

\section{The object of the investigations}

The object is lighting media in industrial buildings, with respect to solar affect, due to insolation through openings. Strictly speaking, solar gains in buildings under discussion are not only restricted, but completely prohibited. This is explained by a number of reasons among which the most important are: extra heat gains and visual discomfort due to brightness and glare. That's why the insolation must be minimized. In practice, the efficient, though cheap mean to struggle negative effect of insolation are sun-protection devices. These

${ }^{*}$ Corresponding author: SCHelokovaTN@mgsu.ru 
elements, acting within the "passive" method of design and construction are widely used today for sun-protection of windows. Among them the most popular are canopies, jalousies, shutters, blinds, etc. [2-16]

But, unfortunately, all these elements are rarely employed for sun-protection of structural units of roof lightning system. So, we have to consider these sun-protection elements, applied on roof structural units of natural lighting system and evaluate them on the basis of lighting and sun-protection comparison analysis.

\section{Comparison analysis}

This should be carried out on comparing both positive and negative characteristics of different types of structural units, which functionally provide the natural illumination of interiors within roof lighting system. Namely, these are: sheds, skylights and monitors, which are illustrated on Figures 1, 2, 3, 4. In Table 1 the lighting and sun-protection characteristics of these structures are being summarized [9-13].

Sheds. These on-roof structures were specially designed for efficient sun-protection. The one-side glazing of sheds is specially made for this purpose, oriented are sometimes termed "north lights", of course, in the case of their implementation in north cemi-sphere regions. One-side glazing of sheds, with no doubt, reduces the light flow inside a building, but he shape of roof near them ensures reflection of light flows, especially in the case of sunny climate conditions. As a result, the lighting of interiors is provided mostly by natural light from the skyvault or/and sun, reflected two times from roof surface and inner surface of a shed (figure 1) [1-5].

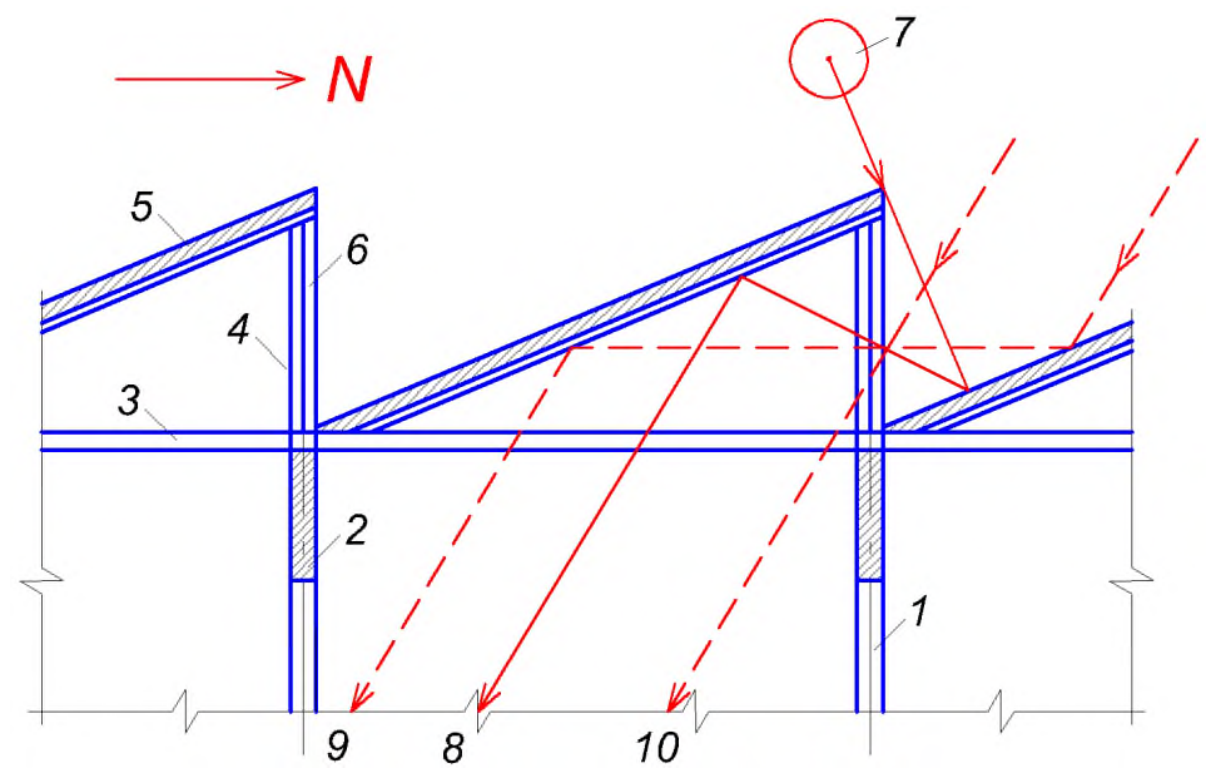

Fig. 1. The scheme, showing light gains into a building with shed lighting roof structure. Key: $1-$ columns; 2 - girders; 3 - purlins; 4 - shed framing; 5 - shed roofing; 6 - side glazing; 7 - the Sun; 8 - sunlight reflected from roofing; 9 - skylight, reflected from roofing; 10 - direct light from the sky.

Monitors are the most traditional and popular roof lighting structures, which are used for lighting as well as ventilating units at he same time. Monitors in their original view have twoside glazing and are not appointed for sun protection. This property of monitors occurs only with implementation of sun-protection devices. In addiction, in hot and sunny climatic conditions, to activate the ventilating process the glazing is sometimes omitted. This also 
results in improving the characteristics of indoor lighting media, even with presence of sun protection devices. (figure 2) [6-8].

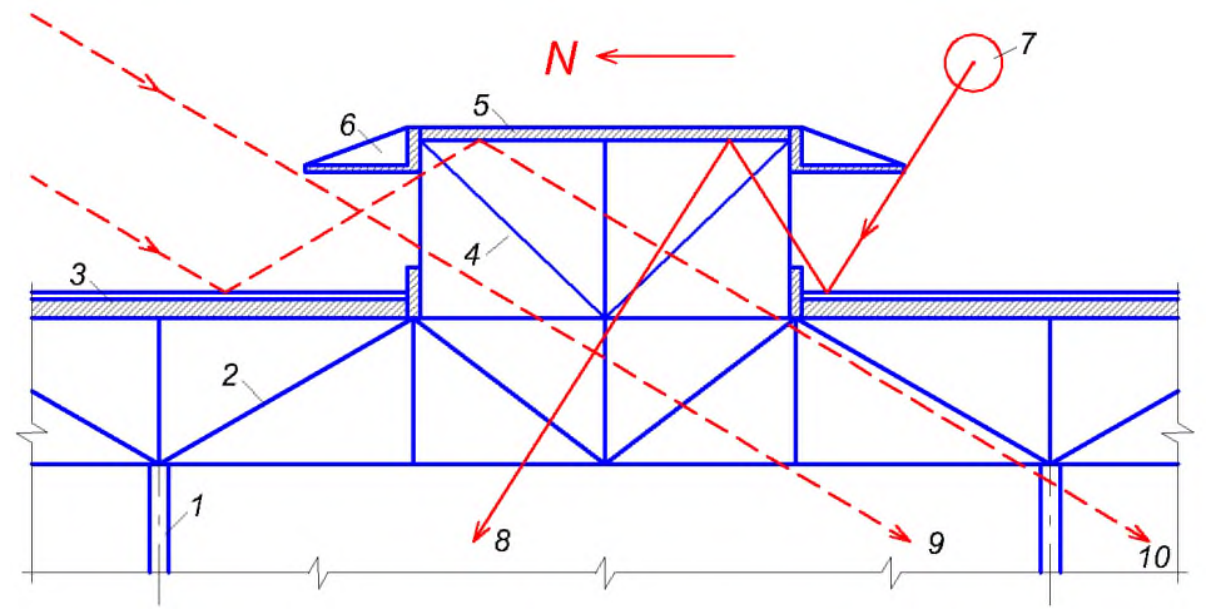

Fig. 2. The scheme, showing light gains into a building with monitor lighting roof structures, furnished with sun protective devices in form of canopies. Key: 1- columns; 2 - roof truss; 3 roofing; 4 - monitor framing; 5 - monitor roofing; 6 - canopy as a sun - protection device; 7 - the Sun; 8 - sunlight reflected from roofing; 9 - direct light from the sky; 10 - skylight, reflected from roofing.

In both two examples, considered above, the reflected light flows from sky and sun have two stages of reflection: the first one - from the upper surface of roofing and the second one from lower surface of shed or monitor coverings. [8-13]

Skylights. These structural units are the most efficient from natural illumination point of view. The majority of external light income which penetrates into an interior in form of direct sunlight or skylight. The reflection from the bearing or/and enveloping structures is minimum. But, unfortunately, negative affect of solar radiation in form of overheating, glares and discomfortable contrasts in this case of skylights use is maximum. Hence, for skylights the implementation of sun-protection device is obligatory. And this leads not only to positive sun-protection, but also reduces the natural lights penetration into the interiors (figures 3 and 4). [9-12]

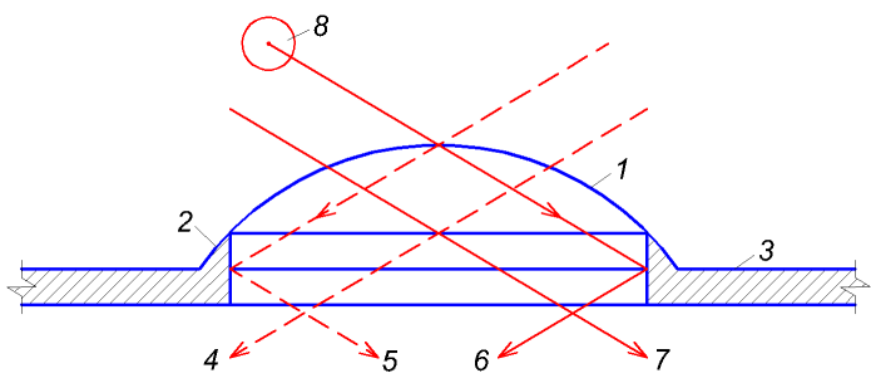

Fig. 3. The scheme, showing light gains into a building with skylight roof lighting structures. Key: 1 - skylight' transparent dome; 2 - skylight supporting structure; 3 - roofing; 4 - direct light from the sky; 5 - reflected light from the sky; 6 - reflected light from the sun; 7 - direct light from the sun; 8 sun. 


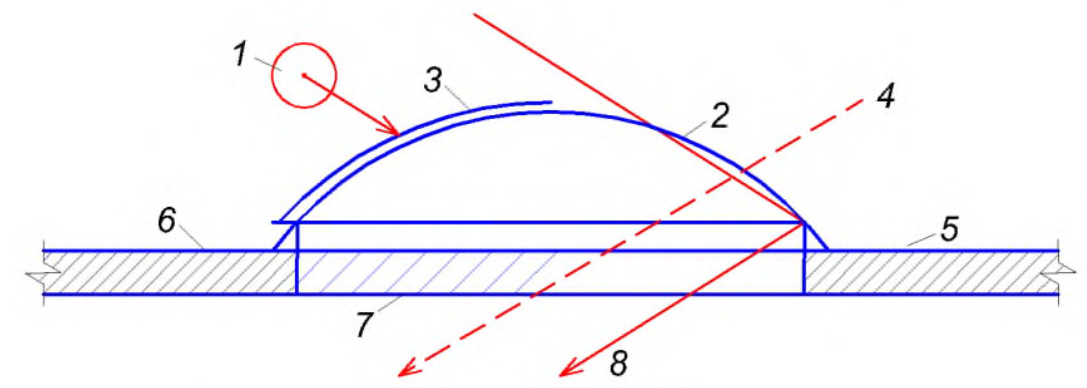

Fig. 4. Stationary and adjustable sun-protect devices, traditionally used in skylights. Key: 1 - the sun; 2 - transparent dome of a skylight; 3 - sun protecting blend, shutter, covering, etc; 4 - direct light from the skyvault; 5 - roofing; 6 - skylight supporting structure; 7 - jalousies, blends, shutters, textile curtain, etc; 8 - reflected sunlight.

\section{Main results}

Table 1 presents the main results of the study, which are obtained on the comparison analysis of positive and negative characteristic of different roof lighting units, illustrated, described and discussed above.

Table 1. The evaluation of main characteristics of microclimatic indoor environment, due to the use of sun-protection devices on different types of roof lightning structures.

\begin{tabular}{|l|l|l|l|l|}
\hline № & $\begin{array}{l}\text { Main characteristic of the } \\
\text { indoor environment }\end{array}$ & $\begin{array}{l}\text { Type 1 } \\
\text { Sheds } \\
\text { (without SPD) }\end{array}$ & $\begin{array}{l}\text { Type 2 } \\
\text { Monitors } \\
\text { (with SPD) }\end{array}$ & $\begin{array}{l}\text { Type 3 } \\
\text { Skylights } \\
\text { (with SPD) }\end{array}$ \\
\hline 1 & 2 & 3 & 4 & 5 \\
\hline 1 & Natural illumination & + & + & $+/-$ \\
\hline 2 & Insolation restriction & + & + & + \\
\hline 3 & Natural ventilation & - & + & - \\
\hline 4 & $\begin{array}{l}\text { Contact with the outdoor } \\
\text { environment }\end{array}$ & $+/-$ & + & - \\
\hline 5 & Visual comfort & $+/-$ & + & - \\
\hline 6 & Solar radiation, heat gains & - & $+/-$ & $+/-$ \\
\hline
\end{tabular}

Note 1. «SPD» is a shortening for sun - protection devices.

Note 2. The content of the table consist of a number objective and subjective characteristics, which are being evaluated with positive, negative or neutral marks with use of "+", "“-" or "+/_" sings for every type of the lighting unit type.

\section{Conclusion}

As the study shows, the best type of roof lighting structure is a monitor, provided with ordinary canopies, as sun-protection device (SPD). Such a design solution is the best for regions with hot and sunny climate, especially for an industrial buildings. Being cheap and fast to construct, monitors provide the majority of positive evaluation of the major physical and functional characteristics of the inner micro-climate environment of buildings in question. 


\section{References}

1. N. M. Gusev, Fundamentals of building physics (Moscow, Stroyizdat, 1975)

2. N. M. Gusev, N. P. Nikolskaya, N. V. Obolensky, Solar radiation and its account in contemporary construction Scientific works of Scientific-research institute of building Physics (NIISF). Lightning Reserch and technology series, 5 (Moscow, 1972)

3. N. M. Gusev, N. V. Obolensky, B. A. Dunaev, et al., Sun protection means application manual Scientific works of Scientific-research institute of Building Physics (NIISF) Lighting research and technology series, 5 (Moscow, 1972)

4. A. K. Soloviev, Environmental phisics (Moscow, ASV publishers, 2014)

5. N. V. Obolensky, Architectural Physics (Moscow, Stroizdat, 1997)

6. M. Tvarovsky, Sun in architecture (Moscow, Stroizdat, 1977)

7. E. Harkness, M. Mehta, Solar radiation control in buildings (Moscow, Stroizdat, 1984)

8. A. K. Soloviev, The efficiency of roof natural lighting of industriel buildings Doctor of science thesis (Moscow, 2010)

9. M. A. Salo, The increase of natural lighting systems efficiency in industrial buildings of Syria (on examples of food industry enterprises) Ph.D. Thesis (Moscow, 2005)

10. S. V. Stetsky, To a problem of indoor microclimatic environmental conditions' subjective appraisal SMOT of XXI century, 2 (2008)

11. A. K. Soloviev, The reflected light influence account for natural illumination design of industrial buildings with roof lighting openings under non-uniform spread of light, Collections of works of Architectural chair of Moscow civil engineering institute, 103 (Moscow, 1974)

12. A. K. Soloviev, The lighting environment appraisal in industrial buildings under «clear sky» conditions, 1 (Svetotechnika, 1987)

13. S. V. Stetsky, Improvement of the internal light environment on the objects of transport infrastructure with aid of sun-protective devices I.O.P. Conference series: Earth and environmental science, 90, 012222 (2017)

14. Blinds and shutters. Thermal and visual comfort European standard - final draft. European Committee for standardization (Brussel, Belgium, 2012)

15. "Solar shading for low-energy buildings" European solar - shading organization. February 2012, 1 (MEISE, Belgium, 2020)

16. "External blinds - performance Requirements, including safety" European Committee for standardization (Brussel, Belgium, 2004) 